\title{
Entre o bas-fond e o high-life: a sexualidade fronteiriça das personagens de João do Rio
}

\author{
Between bas-fond and high-life: the frontier sexuality of characters of João do Rio
}

\author{
Valdemar Valente Junior ${ }^{*}$ \\ Universidade Castelo Branco \\ Rio de Janeiro, RJ, Brasil
}

Resumo: Este artigo tem por objetivo uma abordagem acerca da transgressão sexual como tema recorrente em alguns contos de Dentro da noite, de João do Rio. Ambientados no Rio de Janeiro da primeira década do século XX, ocasião em que ocorre a reurbanização da cidade, configurando uma espécie de belle époque de feição tropical, os contos abordados evidenciam o surto de desenvolvimento em meio às contradições referentes ao atraso social e à dependência econômica que situa o país na periferia do capitalismo. Em vista disso, a condição implícita nos temas que aborda diz respeito às transgressões inerentes ao corpo, referendando um dandismo de superfície que serve para aprofundar os conflitos da modernização excludente que não contempla o conjunto da sociedade, sendo responsável pelo abismo social que se se pode observar.

Palavras-Chave: Belle Époque tropical. Decadentismo. Sexualidade. Degradação.

Abstract: The purpose of this study is to approach sexual transgression as a recurring theme in some of the tales of Dentro da Noite, by João do Rio. Set in Rio de Janeiro in the first decade of the twentieth century, when the reurbanization of the city takes place, the short stories show the development outbreak amid the contradictions regarding social backwardness and economic dependence that places the country on the periphery of capitalism. In view of this, the implicit condition in the themes that it addresses concerns the inherent transgressions of the body, commending a surface dandyism that serves to deepen the conflicts of exclusionary modernization that does not contemplate the whole of society, being responsible for the social abyss that can be observed.

Keywords: Tropical Belle Époque. Decadentism. Sexuality. Degradation.

\section{INTRODUÇÃO}

A figura bizarra de João do Rio pontifica nas duas primeiras décadas do século XX como expressão de um dandismo que tem origem como caricatura do estilo e da forma de se apresentar do que foram logo antes Oscar Wilde e Jean Lorrain, mestres do cerimonial decadentista que em seu estertor se transfere como modelo acrítico para o Rio de Janeiro, a partir das reformas empreendidas pelo prefeito Pereira Passos. Vale lembrar que a postura municipal, tendo em vista a demolição dos pardieiros infectos do Centro, para efeito do alargamento das artérias cronicamente congestionadas, recupera um modelo que se efetivara na Paris de quatro décadas antes, através da postura semelhante adotada pelo barão Haussmann, então prefeito da cidade. A partir do exemplo do Rio de Janeiro, essa mudança, ainda que necessária, chega de modo tardio, contemplando

*Doutor em Ciência da Literatura pela Universidade Federal do Rio de Janeiro. E-mail: valdemarvalente@gmail.com 
modelos estéticos em desuso na Europa às vésperas da Primeira Guerra Mundial, tendo em vista que a urgência das transformações impostas pelo século XX determina a relação com postulados de movimentos de vanguarda como o Cubismo e o Futurismo que passam ao largo da discussão que se efetiva nas hostes cariocas, onde Anatole France e Gabriele D'Annunzio são influências inquestionáveis.

Nesse cenário, João do Rio desfila por entre os escombros do que restou e os espaços que se impõem, visitando albergues, tendinhas e cortiços, do mesmo modo que salões, cassinos e teatros, tendo em vista a ampliação de seu leque de visão acerca do espaço urbano como agente da degradação que atinge diferentes classes sociais. Diante disso, o escritor e o jornalista incorporam na mesma pessoa o desejo de percorrer os escaninhos da cidade na busca por sensações que os levem a materializar a escrita de alguns de seus contos, romances e reportagens mais significativos. Do ponto de vista dos contos, alguns se configuram como expressões nítidas da transgressão sexual como fator que corrompe a ordem social, na condição de elemento capaz de de gerar uma expectativa de prazer que se coaduna ao primado do consumo. A dinâmica de uma economia dependente, no caso brasileiro, que se configura a partir do processo de industrialização que assume feição definida com o século XX, impõe patamares ilimitados ao acesso a bens a que o dinheiro pode adquirir. Entre esses produtos, parece pontificar uma gama de posturas transgressoras que têm na luxúria um elemento acessível aos diferentes setores sociais, das elites à ralé, havendo, por conseguinte, uma sequente troca de lugares.

Desse modo, a ficção que elabora, a partir de alguns de seus contos mais significativos, coloca em questão a sociedade carioca sob as marcas de uma sexualidade que se exercita a partir do fetiche decorrente dos apelos do corpo gravemente afetado pelo desejo de imiscuir-se, tendo em vista a demanda de um consumismo smart que reduz todas as expressões da sexualidade à condição de mercadoria. Por esse meio, a narativa de João do Rio assume a condição de uma nova ordem no que se refere ao consumo, na qual a sexualidade passa a ter lugar, a partir de um primado do prazer a que se faz necessário atingir a qualquer custo, tendo em vista a aquisição de bens materiais onde se inclui o corpo como parte desse processo. Por conta disso, degenerescência física não diz respeito a apenas um único setor da sociedade, o que quase sempre se atribui ás camadas mais pobres, passando a fazer parte do desejo coletivo em suas variadas acepções. O lesbianismo, o fetiche e a depravação assumem espaços no repertório dessa narrativa como acepipe a ser degustado em suas mais variadas formas.

Assim, a publicação de Dentro da noite (1910) traz à luz situações que envolvem a sexualidade como afirmação do vício e da compulsão que se aliam ao desejo de obtenção que se estende dos objetos às pessoas. Por essa via, a narrativa corresponde às posturas desprovidas de pudor de uma sociedade que tem pressa, e que por esse motivo pensa ser possível usufruir de todas as formas de prazer que o corpo pode oferecer. As punções eróticas, o fetichismo e os desejos obscuros são formas que se legitimam nos contos de Dentro da noite, a partir de um dado inusitado que supera a esfera das ptologias já vistas pela estética naturalista para afirmar a condição plena de um ethos transgressor que se atém aos detalhes do corpo como depositário de tudo quanto se faz possível adquirir. Mais ainda, a sexualidade em suas diferentes formas não tengencia em momento algum o 
conceito moral, havendo uma diferença significativa no fato de que a obra de João do Rio coloca-se como herdeira de elementos que retomam o fin-de-siècle europeu e toda a sua carga erógena.

Em vista disso, o cenário de ação do Rio de Janeiro, a partir das modificações impostas pela ordem pública, concorre como elemento primordial à efetivação de um contexto literário que propicia uma abertura ao sentido da fruição do prazer a serviço da burguesia que assume postos, a partir da ascensão das oligarquias rurais à esfera pública da Primeira República. Essa plutocracia que assume os espaços de poder da Capital Federal acaba por dividir essas instâncias entre grupos de apadrinhados que ajudam a articlar o xadrez de uma política para a qual concorrem como peças desse jogo. Assim, os privilégios dessa casta se estendem a um diletantismo que acaba por franquear o acesso do poder às várias possibilidades de obtenção do prazer, dos mais elegantes aos mais expúrios, o que se apresenta como tema em Dentro da noite, onde uma legião de seres à deriva acaba por naufragar no mar do vício e da prostituição, quando a obsessão e o descontrole os fazem descer ao patamar mais baixo da degradação. Nesses termos, as personagens tornam-se possuídas por uma força capaz de lhes roubar a razão, em nome das expressões de um prazer que se confunde com a dor, em uma espécie de paroxismo que lhes pode conduzir à morte.

$\mathrm{Na}$ concepção do presente texto, os contos "Histórias da gente alegre", "O bebê de tarlatana rosa" e "O carro da Semana Santa" contribuem na configuração de uma análise acerca dos diferentes caminhos da sexualidade, quando os corpos se aproximam, aprofundando as contradições de gênero e classe social, ao apontar para as possibilidades de fruição do prazer e da dor. Desse modo, a discussão envolvendo gênero e sexualidade, a partir de uma escrita concebida há mais de um século, reforça a condição desse tema vir a funcionar no tempo presente, em vista da abertura que as manifestações da sexualidade assumem como postura preponderante. A transgressão que se efetiva induz a um clima de despudor que em em alguns casos tangencia o paroxismo das relações envolvendo a degradação de sentido coletivo, na medida em que as cenas explicitam-se por ocasião de acontecimentos coletivos, no exemplo dos festejos do Carnaval, em "O bebê de tarlatana rosa", e da procissão da quinta-feira da Quaresma, em "O carro da Semana Santa", além do vício da morfina e do lesbianismo, em "Histórias da gente alegre". A isso se acrescenta o cinismo social que tende a lidar com essas situações como se a elas não correspondesse nenhuma forma transgressora, ficando as mesmas restritas apenas a uma condição de artificialismo.

\section{SEXO E VIOLÊNCIA}

A narrativa de João do Rio insiste em convocar a figura do Barão Belfort para servir como mestre de cerimônias das aventuras que nela se sucedem, envolvendo o prazer que o velho dândi possui em testemunhar a derrocada dos que chafurdam inevitavelmente, dominados pela luxúria e pelo vício. Por esse meio, explicita-se o lugar do dândi. "Além de não ter um objetivo, ele se imola em nome dessa ausência. Do princípio ao fim, até a morte, sua vida é gratuita, sem razão real'". (BOLLON, 1993, p. 207-208). Em certas 
ocasiões, para além da condição de narrador a quem cabe desenvolver o enredo de que tratam alguns contos, o Barão Belfort agencia diretamente a decadência dos que são desprovidos de força suficiente para sobreviver à decadencia a que são condenados, na condição de incautos que se arvoram à fruição dos prazeres do corpo como parte de sua natureza essencial. Disso decorre a fleugma com que são narrados esses episódios como uma espécie de alimento ao espírito de quem não manifesta qualquer espanto diante do sexo como expressão da miséria humana em sua condição absoluta. Por causa disso, o Barão Belfort se compraz em narrar a forma insidiosa através da qual jovens cheios de vigor são tocados pelo vício e pela prostituição que os arruína, como se a isso pudesse corresponder a absorção da seiva da vida que prolonga os anos do velho libertino, para quem não há outro meio de aproveitar o transcurso dos anos.

Daí o eixo das ideias do conto "Histórias da gente alegre" recair no drama de Elsa d'Aragon, quando a narrativa que envolve sua morte passa a ser descrita com requinte pelo Barão Belfort como um acontecimento banal, enquanto pede o cardápio ao garçom, à mesa de um clube de jogo. O vício do champanhe, do ópio, do éter e da morfina acompanham a jovem prostituta, na medida em que se vê obrigada por um intermediário, bem como pela dona da pensão onde trabalha, a atender de forma incansável a uma clientela endinheirada que nela despeja todas as taras e transgressões do sexo. Para completar sua infelicidade, o que consegue ganhar ao mercadejar o corpo é dilapidado sem a possibilidade de que lhe seja garantido um pecúlio, em face da velhice prematura, uma vez que a morte se anuncia em tempo breve. "A franja fúnebre, que roça insistentemente o texto decadentista, constitui-se, também, numa reação contra a objetividade realista-naturalista, ao celebrar o mórbido cerebral e narcísico, a atração erótica pela decomposição e pela morte. (MUCCI, 1994, p. 89.). Diante disso, o artificialismo das relações marcadas pela presença de personagens sem a mínima compaixão para com o próximo alimenta um universo de sensações provisórias que se evaporam como o champanhe e o éter, entorpecendo como o ópio e a morfina, e aliandose às manifestações de uma sexualidade que se faz experimentar de diferentes formas.

Os limites do corpo atingem o paroxismo completo, na medida em que Elsa d'Aragon se aproxima de Elisa, com quem estabelece um relacionamento no qual o homossexualismo se funde ao uso de entorpecentes, levando ambas à via do paraíso artificial como uma espécie de viagem sem retorno. Trancadas no quarto da pensão de mulheres, onde Elisa d'Aragon atende a seus clientes, as duas entram em luta corporal, e o desenrolar dessa pugna resulta na vitória de Elisa, que regurgita sua fúria sobre o cadáver da amante. "É o sadismo que é o Mal: se matamos por uma vantagem material, não é o verdadeiro Mal, o mal puro, a menos que o assassino, para além da vantagem com que conta, goze simplesmente por golpear". (BATAILLE, 2015, p. 15-16.). O desfecho da tragédia, narrada pelo Barão Belfort, dá conta de que a dona da pensão evita a presença da polícia, dando-se o sepultamento de Elsa d'Aragon ao tempo em que Elisa é conduzida a um manicômio. Assim, a relação entre o amor e a morte chega ao clímax de uma situação para a qual não há formas de resistência, parecendo decorrer de um determinismo de forças que se sobrepõem à mera condição humana. Elsa d'Aragon e Elisa caracterizamse como situação limítrofe entre o amor e a morte, quando a última se impõe de modo a 
não permitir que paire qualquer dúvida acerca do sentido destrutivo que marca essa relação.

A dor e o prazer, portanto, permeiam o desenrolar das ações em que as duas mulheres se expõem para além da condição do que representa a sexualidade, tendo em vista que os entorpecentes que consomem lhe agenciam o embrutecimento da razão, de onde decorre o mergulho no poço sem fundo da loucura e da morte. No entanto, a necessidade de aviltar o próprio corpo não se apresenta como condição exclusiva das duas amantes, senão como um desejo que se expande a certo tipo de sociedade smart descrita como uma grã-finagem ociosa que já não encontra nenhum prazer na sucessão de banalidades do cotidiano. Desse modo, o sexo apresenta-se como meio capaz de levar ao êxtase e reduzir ao caos das situações que se afirmam como expressões de obtenção do prazer em níveis inimagináveis. "O estupro, o espancamento e até o assassinato de mulheres frequentemente contêm os mesmos elementos básicos que os encontros heterossexuais não-violentos, quais sejam, a dominação e a conquista do objeto sexual". (GIDDENS, 1993, p. 137.). Por sua vez, a figura do Barão Belfort apresenta-se envolvida por um halo de ambiguidade que lhe sugere a condição singular de quem observa a cena do amor e da morte a partir de um distanciamento que lhe permite usufruir desse transe sem vir a tomar parte direta nesses acontecimentos, nos quais interfere como narrador. Daí o prazer que se confirma na representação do outro como parte integrante de sua própria degradação.

As expressões de uma sexualidade que levam ao aniquilamento apresentam-se em "Histórias da gente alegre" como tema inusitado no contexto da produção narrativa do período em que João do Rio pontifica como escritor, a partir de um ethos que o caracteriza como autor pioneiro, no que se refere às manifestações da sexualidade como formas decorrentes de um prazer de natureza egocêntrica. As questões que envolvem a legitimação desse prazer não interferem no fulcro da narrativa, uma vez que ela se apresenta completamente despida de conceito moral. No entanto, essas representações do transtorno que acomete as personagens de João do Rio, de um modo mais amplo, concorrem para que a partir dos vários exemplos extraídos de sua obra se possa configurar um corpus capaz de dar conta em âmbito satisfatório de discussões pendentes a respeito da sexualidade ao longo do tempo. "Ao criar personagens, o escritor dá forma aos aspectos conflitantes de seu interior, para poder examiná-los. Desta maneira, o distúrbio em sua vida pode ser entendido”. (DESALVO, 1998, p. 27.). Mais que isso, sua posição, em vista o período em que vive e escreve, parece por momentos ampliar a possibilidade desse debate na direção de temas que envolvem a concepção de gênero, o que àquela altura dos fatos se apresenta como proposta intangível, no rol dos assuntos a que a literatura ainda não ousa tocar. Por conta disso, justifica-se o silêncio de décadas a respeito de sua obra, só recentemente trazida de volta à luz dos fatos.

As personagens que frequentam os subsolos, a partir de situações que não constam nas estatísticas da cidade, no transcurso de sua atividade cotidiana, são expressões camufladas de um mundo particular onde dândis e sibaritas expõem seus desvios de conduta servindo-se do vício e da prostituição como elementos que definem a condução de seus atos. O prazer que consiste em narrar a morte brutal de uma mulher dominada 
pelo vício funciona como elemento capaz de levar o Barão Belfort a exercitar sua hiperestesia de modo semelhante ao que ocorre no transe sexual que conduz à morte e à loucura. Por esse meio, a narrativa aproxima os lados opostos da miséria humana, não se atendo apenas ao maniqueísmo de denunciar o drama social como elemento único, na medida em que aponta para os descaminhos de uma condição intrínseca ao que pode atingir os que se arriscarem no lodaçal da perversão. "À medida que se iniciava o século $\mathrm{XX}$, as duas principais tendências do século anterior - o culto do super-homem e a preocupação relativamente recente pelo sofrimento humano - ainda estavam ambas em evidência". (THOMPSON, 2002, p. 489.). Assim, o desejo de enlamear-se não escolhe classes, uma vez que, em essência, todos são perversos, cada qual exercendo a seu modo a situação viciosa que lhe cabe, a partir de um mundo impiedoso onde se tenta a sobrevida dos náufragos.

\section{UM CORPO NA MULTIDÃO}

O Carnaval como acontecimento capaz de deflagrar os mais abjetos instintos humanos não parece se constituir em novidade, uma vez que a máscara por trás da qual se esconde cada um dos que buscam nessa festa omitir sua face verdadeira, por conta do sentido de desvio da conduta, considera que nesses três dias tudo seja permitido. Diante disso, a festa da carne potencializa os mais recônditos desejos, em nome da ruptura de tabus que se configuram, com relação ao comportamento das pessoas nos dias restantes do ano. Assim, retirar a máscara se representa o ponto alto dessa festa, quando não se faz mais preciso nenhum disfarce que sirva para cobrir o que se esconde por trás da transfiguração, do mesmo modo que a nudez e o despudor são cobertos por véus, antecedendo a quaresma, ocasião em que a castidade passa a impor suas formas de expressão e fruição dos prazeres da vida. "Uma boa vida não é aquela a serviço de Deus e da moral, nem de seus substitutos modernos coletivos, a Nação, a República ou ainda as Luzes; uma boa vida é aquela que sabe se tornar bela". (TODOROV, 2011, p. 25-26). Por isso, o Carnaval concorre para que a luxúria se apresente em face de um desejo que atua de modo a liberar as energias represadas no transcurso do ano, quando o ordenamento trivial das coisas concorre para que se estabeleçam formas de contenção das punções eróticas que se acumulam, não obstante o instinto transgressor dos que não se contentam apenas com a folia momesca.

Desse modo, em "O bebê de tarlatana rosa" explicitam-se os instintos de Heitor de Alencar, que narra, em meio a uma roda de amigos, acerca da aventura vivida por ele durante o Carnaval. Em companhia de uma troupe de atrizes francesas, a excitação chega ao clímax quando esse grupo visita cassinos luxuosos, onde se bebe o melhor champanhe e os elegantes do jet-set pontificam, e maxixes ordinários, onde pulula uma turba disforme e as brigas se sucedem. Assim, o êxtase consiste na oscilação desses prazeres. "Naturalmente, sendo o comportamento da elite burguesa o referencial para os outros estratos sociais, a moda dos bailes de máscaras se espalhou pela cidade, sendo realizados tanto nos mais sofisticados salões privados, quanto em redutos populares periféricos". (GÓES, 2006, p. 51). Daí a necessidade de acanalhar-se, como sugere o narrador, chegar 
ao limite extremo, quando as libações e os transes eróticos deixam de fazer sentido, na medida em que se torna imperativo vivenciar outras sensações em níveis inatingíveis. Assim, a narrativa atinge seu ponto mais elevado no que se refere à insatisfação que a caracteriza em meio às sucessivas tentativas de supressão de um desejo que acabam em vão. Para tanto, interfere a constatação do sentido inócuo dos seres diante do nada que representa a solidão coletiva da multidão que se congrega em torno do tríduo momesco. A compactação dos corpos amontoados, em virtude da festa, sugere a fruição de um prazer que se volatiza, do mesmo modo que incorpora um significado de sentido coletivo.

O surgimento em meio à multidão de uma bebê fantasiado de tarlatana cor-de-rosa desvia o sentido do que até então parecia dar significado ao conto, quando Heitor de Alencar, ao receber de volta o flirt que lhe lançara, resolve abandonar seus companheiros em busca do desejo diante do qual se perde no tumulto da celebração, misturando-se à turba de feição indefinida. "A atomização da cidade colocou um fim prático num componente essencial do espaço público: a superposição de funções dentro de um mesmo território, o que cria complexidades de experiência naquele determinado espaço". (SENNETT, 1988, p. 362.). Cabe ainda lembrar que o título do conto remete à ideia de uma indefinição, no que se refere à dicotomia entre masculino e feminino, na medida em que a palavra bebê se apresenta como elemento comum aos dois gêneros. Desse modo, a aventura que Heitor de Alencar empreende à procura do bebê não subentende ter como fim a fruição do prazer por conta do contato com um homem ou uma mulher, o que parece se neutralizar, a partir da definição de gênero que a narrativa deixa de explicitar. A postura assumida por Heitor de Alencar, do mesmo modo, não reivindica nenhuma preferência que exponha o significado de gênero ou sexo, o que concorre para que a narrativa de João do Rio se confirme como expressão singular, postando-se a contrapelo da ficção que predomina por esse tempo.

Assim, o desejo de Heitor de Alencar passa a individualizar o que até então seguia o curso de uma vontade que a ele agrega outras figuras, de que se separa para ir ao encontro do bebê por quem seus instintos foram vivamente tocados. Por esse meio, não resta outra alternativa senão bracejar no mar da orgia, permitindo-se a toda sorte de licenciosidades que o Carnaval confere em sua configuração de festa profana. A sucessão de práticas permissivas que envolvem as punções erógenas faz com que os corpos se apresentem como receptáculos aos quais parecem franqueadas as possibilidades de fruição de um desejo sem medida. "Nesse universo de aparências, o desafio, portanto, era manter claras as diferenças entre as classes, tendo em vista que as identidades se simulavam a partir da capacidade de consumo de cada um". (DONATO, 2006, p. 204). Desse modo, a peregrinação de Heitor de Alencar, em meio à turba ensandecida pelos apelos da luxúria, visa exclusivamente encontrar o bebê cujo apelo de sedução o fizera desviar-se do roteiro a que previamente estabelecera. Nas ondas do mar da luxuria, um náufrago perdido procura por uma tábua de salvação que se explicita na condição única de encontrar o bebê antes que a festa se encerre, na medida em que o adiamento desse encontro deixaria de fazer sentido. Mais ainda, o Carnaval subentende a revelação da imagem real dos que se ocultam em máscaras que na quarta-feira de cinzas devem ser retiradas. 
O predomínio do desejo individual sobre o coletivo permeia as ações em "O bebê de tarlatana rosa", impondo regras que se sobrepõem a um suposto desregramento, quando as vontades se mostram superiores a qualquer outro apelo, resultando disso a supremacia do físico sobre o mental, ou ainda, do ilógico sobre o lógico. Mais que isso, o desejo incontido que o bebê desperta em Heitor de Alencar decorre de um plano de satisfação que se atém ao essencialmente rápido. Isso se faz suficiente para que a condição amorosa se manifeste em sua força, impondo ao desejo libidinoso uma superioridade presente como objetivo único, de onde demanda a insaciabilidade em sua cegueira de sentido e razão. A isso se acrescenta a reaparição do bebê, ao final da festa, quando pierrôs e mascarados retornam às suas casas, cansados da orgia, a partir do mesmo sentido de surpresa de sua primeira aparição. Daí o intuito de Heitor de Alencar ser permeado pelo êxito de quem perseguira sem trégua a ideia do reencontro com o bebê que se perdera em meio à multidão nos dias de Carnaval. "A cidade é a realização do antigo sonho humano do labirinto. O flâneur, sem o saber persegue essa realidade.” (BENJAMIN, 1991, p. 203). A obsessão que se confirma nessa busca caracteriza, do mesmo modo, um dos sintomas da transgressão que deposita em um único objetivo toda a sua carga de perversão erógena.

O desfecho da narrativa acaba por fraudar as expectativas de Heitor de Alencar, no sentido do que o disfarce de papelão e cera do bebê escondem a ausência de seu nariz. Ao ter arrancada a máscara, que configura o fim da festa, surge aos olhos de Heitor de Alencar o lado horrendo do bebê que possui um buraco sangrento no lugar das narinas devoradas pela doença. "Esboços precários de ficção dissimulada movem-se com a plenitude das personagens em estado puro, sustentados por uma cumplicidade irônica do narrador com a vantagem de chegarem ao leitor como fratura exposta que não comporta retoques". (PRADO, 2004, p. 61). Diante do impasse que se estabelece, resta a justificativa de quem se serve de uma máscara para encobrir a deformidade como empecilho à fruição do desejo no restante do ano, cabendo ao Carnaval a via dessa possibilidade, uma vez que o evento dá margem a que todos possam de algum modo disfarçar-se, ao esconder provisoriamente sua verdadeira feição. O sentido mórbido presente em "O bebê de tarlatana rosa" denuncia a supremacia de um ethos em que o aviltamento da relação entre eros e tanatos deflagra um processo que parece ter azo apenas no âmbito da narrativa, ao diferir das instâncias de realidade. Por sua vez, os contos de João do Rio apresentam-se como elementos que se agregam às crônicas que escreve ao sabor da hora, trazendo para o jornalismo diário a dor e o prazer que fundamentam a tragédia humana em sua condição mais plena.

\section{O PRAZER E A RUÍNA}

O cortejo do Senhor Morto, na quinta-feira de endoenças que antecede a SextaFeira da Paixão, é descrita no conto "O carro da Semana Santa" como retrato escatológico que se contrapõe à cerimônia marcada pelo recato, por ocasião da efeméride em torno da morte e da ressureição de Jesus Cristo. $\mathrm{Na}$ condição de texto que se faz representar a partir da voz de um determinado narrador, João do Rio se serve de um certo Honório, personagem que não figura entre os demais na galeria dos tipos que cria, para dar conta dos episódios em que turba se comprime em torno de uma berlinda conduzida por um 
cocheiro, dentro da qual se oculta o vício e a luxúria de alguém de condição indefinida que se entrega aos prazeres do corpo a toda espécie de gente, pagando em dinheiro por conjunções carnais que se sucedem. "Entre as figuras lendárias nomeadas no final do século XIX, a filha de Herodes é uma das mais frequentes e oferece todas as características de uma obsessão coletiva, na maioria das vezes perfeitamente consciente. (DOTTINORSINI, 1996, p. 128.). O narrador acrescenta ser o terceiro ano seguido que acompanha a procissão do vício, percorrendo o Centro do Rio de Janeiro atrás do cortejo marcado pela imundície. No seu rastro, segue uma ralé representada pelo que há de mais horrendo nos escaninhos da cidade, de onde parece afluir ao mesmo tempo toda a escória que neles se esconde durante o restante dos dias.

Por esse meio, a narrativa de João do Rio assume seu espaço como iniciativa decorrente do estreitamento da relação entre a crônica jornalística e a prosa de ficção, na medida em que, a partir dessa segunda proposta, traz à luz elementos pertencentes ao cotidiano da cidade onde vive, acrescentando-lhes elementos capazes de inseri-los em um plano de verossimilhança que os adequa à dimensão narrativa do que pretende abordar. Assim, a opção pelos temas que remetem aos desvios da sexualidade como elementos recorrentes, diante do que se faz representar, quebra sua hierarquia, unificando as classes sociais em função dos instintos erógenos que as iguala. A rua, portanto, se constitui no espaço onde as diferentes formas de expressão do desejo, assim como os diferentes gêneros da sexualidade se tornam cúmplices, em vista da abertura que o espaço público suscita como ponto aglutinador das posições mais díspares. "A verdadeira crise da cidade manifesta-se não apenas em uma diminuição do seu nível cultural, mas também na perda do seu caráter original de organismo cultural". (ARGAN, 1998, p. 257). Daí "O carro da Semana Santa" trazer para o plano da narrativa a manifestação orgástica da plebe, o que se contrapõe ao sentido de purificação representado pela reverência cristã à paixão do crucificado. A manifestação de luxúria da berlinda onde repousa o sexo promiscuo tende a escandalizar a alguns poucos, a despeito da turba cega que a acompanha.

Diante de uma multidão que se aproveita do evento religioso para dar vazão aos seus instintos perversos, abdicando do sentido de santificação da procissão para exercer as variadas formas de uma sexualidade, o narrador indaga acerca de quem ocupa o interior da berlinda. As dúvidas a respeito de que dentro do veículo esteja um homem ou uma mulher são as mesmas que levam à indagação de ali se encontrar uma mulher da alta sociedade, uma prostituta, uma louca, uma mulher que fora bela, mas se encontra deformada por bexigas, ou ainda, alguém com o corpo queimado ou coberto de pústulas. "No mundo do erotismo há também o negativo, a repugnância. A repugnância para com uma pessoa que vemos pela primeira vez, na rua, ou para com alguém que já conhecemos". (ALBERONI, 1992, p. 87). Daí o senso comum dividir a opinião de que no interior da berlinda se encontra uma senhora de posição social elevada. Diante de tantas indagações, ali está a forma mais odienta do vício e a luxúria mais espúria. $\mathrm{Na}$ verdade, "O carro da Semana Santa" evidencia o lado nebuloso de uma sociedade que busca integrar-se ao mundo civilizado sem abrir mão da carga de transgressão que pulula em meio a um rebotalho humano diante do qual as medidas de assepsia promovidas pela 
municipalidade se mostram ineficazes, ou ainda, parece prevalecer a necessidade das elites em conviver com situações dessa natureza, como denuncia a narrativa.

Há que se pensar que o espaço destinado à procissão da quinta-feira de endoenças, cujo significado reproduz os passos do filho de Deus, tende a se contrapor à representação do pecado que em "O carro da Semana Santa" assume o lugar da degenerescência da condição humana como detentora dos erros que fazem dela uma imitação do trabalho de Deus. Desse modo, não existe salvação diante do que se apresenta como expressão do que cada um traz dentro de si, não podendo ser por outro meio que a aparição da luxúria em meio à celebração religiosa tenha em si o poder de continuar assentido à sagração de que se faz imperativo seguir. Por sua vez, a corrupção presente na multidão tocada pelo desejo de imiscuir-se concorre para que se multipliquem as diferentes expressões do prazer barato. "A desenfreada licença de tratar motivos viciosos e cruéis, introduzida na literatura com o romantismo, criou ambiente favorável à liberação de sensibilidades individuais que, em outro clima, teriam permanecido latentes e sufocadas. (PRAZ, 1996, p. 345.). A horda de mutilados e invertidos de todos os gêneros que se expõe na festa religiosa abre mão do que parece lhes faltar em essência, deixando-se levar pelo oposto do que representa a fé como princípio inalienável da cristandade. Desse modo, os desvios de conduta induzem à negação da purificação do corpo e do espírito na semana de Pentecostes.

As formas inerentes à degradação do sexo como objeto da obsessão humana destoam de sua função ligada ao prazer e à reprodução, na medida em que recorrem ao fetiche e ao sadismo como meios que levam ao paroxismo das relações doentias. Assim, a morte e o prazer se irmanam, a partir dos descaminhos que induzem ao gozo de uma liberdade sem final. Daí os limites do corpo não serem respeitados, o que corresponde à ausência da noção de finitude que deve permear o sentido da matéria. "Resulta daí que, mesmo para os olhos que não querem ver, o retrato da miséria delineia-se como estratégia arrancada da vida, o que torna ambígua a suposta neutralidade do narrador". (PRADO, 2004, p. 60). Para que se possa encontrar uma resposta à falta de sentido inerente à degradação do corpo se faz mister entender o paradoxo do desfile macabro da quaresma como expressão do desejo de aviltar a própria dignidade, presente em "O carro da Semana Santa" como parte integrante de uma ordem de pensamento que diz respeito às indagações decorrentes da virada do século XIX para o século XX como um tempo de profundas transformações e incertezas. O ideário correspondente a esse lapso de tempo reforça a descrença humana acerca dos valores positivos de uma existência que é negada em favor das formas imediatas do prazer.

Diante disso, a preservação do corpo passa a não fazer sentido, no que se refere à entrega compulsiva que se efetiva aos olhos de quem pela primeira vez acompanha o desfile da berlinda macabra. A procissão do Senhor Morto, por sua vez, induz os cristãos à crença da ressurreição depois da morte, dando prosseguimento ao milagre da vida. De modo oposto, o cortejo abjeto investe na deterioração da espécie humana a partir do sexo que se corporifica, quando o espectro da morte e da destruição ronda as ruas e becos do Centro do Rio de Janeiro sob o olhar incauto de quem o presencia em seu rastro de prazer e ruína. Assim, a volúpia humana parece não obedecer a qualquer ordem que a impeça de 
chegar ao limite do que se mostra infindável, na medida em que a certeza da morte indica as múltiplas possibilidades de se gozar a felicidade única da vida. "Há lá, Deus me perdoe, toda a amostragem do vício em nossa boa cidade". (LÉVY, 1989, p. 20). A morte e o prazer subentendem um princípio único do que em "O carro da Semana Santa" representa abrir mão de outros bens que a vida oferece, não sendo possível sobreviver ao tropel devastador de uma sucessão de misérias sem que a isso não se imponha o orgasmo do populacho, em sua expressão mais abjeta.

\section{REFERÊNCIAS}

ALBERONI, F. O erotismo: fantasias e realidades do amor e da sedução. São Paulo: Rocco, 1986.

ARGAN, G. C. História da arte como história da cidade. São Paulo: Martins Fontes, 1998.

BATAILLE, G. A literatura do mal. Belo Horizonte: Autêntica Editora, 2015.

BENJAMIN, W. Charles Baudelaire: um lírico no auge do capitalismo. São Paulo: Brasiliense, 1991.

BOLLON, P. A moral da máscara: merveilleux, zazous, dândis, punks, etc. Rio de Janeiro: Rocco, 1993.

DESALVO, L. Concebido com maldade: a literatura como vingança na vida e na obra de Virginia e Leonard Wolf, D.H. Lawrence, Djuna Barnes e Henry Miller. Rio de Janeiro: Record, 1998.

DONATO, C. Frente e verso da Belle Époque carioca: do objeto de fetiche ao objeto da fé. In: COUTINHO, L. E. B.; MUCCI, L. I. (Orgs.). Dândis, estetas e sibaritas. Rio de Janeiro: Confraria do Vento, Faculdade de Letras da UFRJ, 2006, p. 202-212.

DOTTIN-ORSINI, M. A mulher que eles chamavam fatal: textos e imagens da misoginia finde-siècle. Rio de Janeiro: Rocco, 1996.

GIDDENS, A. A transformação da intimidade: sexualidade, amor e erotismo nas sociedades modernas. São Paulo: Edusp, 1993.

GÓES, F. Entre o traje e a fantasia: uma contenda estética do carnaval na Belle Époque carioca. In: COUTINHO, L. E. B.; MUCCI, L. I. (Orgs.). Dândis, estetas e sibaritas. Rio de Janeiro: Confraria do Vento, Faculdade de Letras da UFRJ, 2006, p. 48-56.

LÉVY, B.-H. Os últimos dias de Charles Baudelaire. Rio de Janeiro: Rocco, 1989.

MUCCI, Latuf Isaías. Ruina e simulacro decadentista: uma leitura de Il piacere, de D’Annunzio. Rio de Janeiro: Tempo Brasileiro, 1994.

PRADO, A. A. Trincheira, palco e letras: crítica, literatura e utopia no Brasil. São Paulo: Cosac Naify, 2004. 


\section{das Letras}

PRAZ, M. A carne, a morte e o diabo na literatura romântica. Campinas: Editora Unicamp, 1996.

SENNETT, R. O declinio do homem público: as tiranias da intimidade. São Paulo: Companhia das Letras, 1988, p. 362.

THOMPSON, O. A assustadora história da maldade. São Paulo: Ediouro, 2002.

TODOROV, T. A beleza salvará o mundo: Wilde, Rilke e Tsvetaeva, os aventureiros do absurdo. Rio de Janeiro: Difel, 2011.

Recebido em: 05/05/2018

Aprovado em: 20/09/2018

Publicado em: 01/12/2018 